\title{
Antibiotic resistance and typing of the methicillin-resistant Staphylococcus aureus clones in Kuwait hospitals, 2016-2017
}

\author{
Samar S. Boswihi, Edet E. Udo ${ }^{*}$ and Wadha AlFouzan
}

\begin{abstract}
Background: Methicillin-resistant Staphylococcus aureus (MRSA) belong to diverse genetic backgrounds that differ in antibiotic resistance. Knowledge of the local clonal composition of MRSA strains is important for patients' management and for designing effective control and eradication methods. The aim of this study was to compare the antibiotic resistance patterns and genotypic characteristics of MRSA isolates obtained in public hospitals in Kuwait in 2016 and 2017 for changes in their resistance patterns and clonal composition.
\end{abstract}

Methods: A total of 4726 MRSA isolates obtained in 2016-2017 from clinical specimens in Kuwait public hospitals were characterized using antibiogram, SCCmec typing, spa typing and DNA microarray.

Results: The isolates expressed resistance to fusidic acid (52.9\%), kanamycin (41.6\%), gentamicin (32.5\%) and erythromycin (36.2\%). The prevalence of high-level mupirocin resistance decreased from 3.7\% in 2016 to $2.4 \%$ in 2017, while the proportion of resistance to other antibiotics remained relatively stable. A total of 382 spa types were detected with eight spa types, t688 $(N=547), \mathrm{t} 304(N=428), \mathrm{t} 860(N=394), \mathrm{t} 127(N=306), \mathrm{t} 044(N=230), \mathrm{t} 311(N=$ 243), t223 ( $N=184)$ and t002 ( $N=181)$ constituting $53.1 \%$ of the MRSA isolates in 2016-2017. Of the 3004 MRSA isolates obtained in $2016(N=1327)$ and $2017(N=1677)$ selected for DNA microarray analysis, 26 clonal complexes (CCs) were identified. Most of the isolates belonged to CC1 $(N=248)$, CC5 $(N=833)$, CC6 $(N=241), C C 8(N=292)$, CC22 $(N=421), C C 30(N=177), C C 80(N=177)$ and CC97 $(N=171)$. The prevalence of CC5 isolates has significantly $(p \leq 0.05)$ increased from 294 isolates in 2016 to 539 isolates in 2017. Although CC22 increased from 196 isolates in 2016 to 225 isolates in 2017, CC1 increased from 112 isolates in 2016 to 136 isolates in 2017, CC6 increased from 103 isolates in 2016 to 138 isolates in 2017, these changes were not significant ( $p \geq 0.05$ ).

Conclusion: These results revealed the diversity in the genetic backgrounds of MRSA isolates and the stable maintenance of the dominant MRSA clones in Kuwait hospitals in 2016 and 2017 suggesting an on-going transmission of these clones. Novel and creative infection prevention and control measures are required to curtail further transmission.

Keywords: MRSA, DNA microarray, Antibiotic resistance, Genotypes, Clonal complex

\footnotetext{
* Correspondence: Udo.ekpenyong@ku.edu.kw

Department of Microbiology, Faculty of Medicine, Kuwait University, Kuwait City, Kuwait
}

\section{$\triangle B M C$}

(C) The Author(s). 2020 Open Access This article is licensed under a Creative Commons Attribution 4.0 International License, which permits use, sharing, adaptation, distribution and reproduction in any medium or format, as long as you give appropriate credit to the original author(s) and the source, provide a link to the Creative Commons licence, and indicate if changes were made. The images or other third party material in this article are included in the article's Creative Commons. licence, unless indicated otherwise in a credit line to the material. If material is not included in the article's Creative Commons licence and your intended use is not permitted by statutory regulation or exceeds the permitted use, you will need to obtain permission directly from the copyright holder. To view a copy of this licence, visit http://creativecommons.org/licenses/by/4.0/. The Creative Commons Public Domain Dedication waiver (http://creativecommons.org/publicdomain/zero/1.0/) applies to the data made available in this article, unless otherwise stated in a credit line to the data. 


\section{Background}

Since its report in 1961 in England [1], methicillin-resistant Staphylococcus aureus (MRSA) has spread to many countries causing serious infections that are sometimes difficult to treat [2]. Initially, MRSA was a well-established pathogen among elderly patients with previous admission to healthcare settings and with history of previous antibiotic usage. This type of MRSA was known as healthcare-associated or healthcare-acquired MRSA (HA-MRSA) [3]. Then in the 1990's, a new lineage of MRSA emerged in people with no previous history of hospitalization or exposure to the healthcare system and previous antibiotic use which was designated as community-associated or communityacquired MRSA (CA-MRSA) [4].

Molecular epidemiological typing techniques, such as SCCmec typing, staphylococcal protein A (spa) typing, multilocus sequence typing (MLST), pulsed-filed gel electrophoresis (PFGE) and DNA microarray have been used to study the genetic background of MRSA. HAMRSA isolates carry relatively large SCCmec genetic element belonging to type I, II, or III, and are usually resistant to multiple non-beta-lactam antibiotics [2]. In contrast, CA-MRSA isolates carry smaller sized SCCmec elements belonging to SCCmec type IV, V or VI and are usually sensitive to most non-beta-lactam antibiotics [2]. MRSA isolates carrying different SCCmec genetic elements have been further differentiated using MLST and eBURST which grouped them into sequence types and clonal complexes (CCs) [2].

Studies have shown that CA-MRSA have replaced HA-MRSA in many countries including Kuwait [5],
Singapore [6], United Arab Emirates [7] and Portugal [8]. A previous study in Kuwait showed that the clonal composition of the MRSA has changed significantly from 1992 to 2010 [5] with the emergence of different CA-MRSA clones. The same report revealed that CC8/ ST239-III remained the most common clone in Kuwait hospitals from 1992 to 2010, although their prevalence decreased overtime [5]. During the same period, the prevalence of CA-MRSA clones including CC5/ST5-IV/ $\mathrm{V}, \mathrm{CC} 80 / \mathrm{ST} 80-\mathrm{IV}$ and ST1-IV/V were increasing [5]. To provide an update on the clonal composition of MRSA strains circulating in Kuwait hospitals, this study compared the antibiotic resistance patterns and genotypic characteristics of MRSA isolates obtained in public hospitals in Kuwait in 2016 and 2017 for changes in clonal composition and resistance profile.

\section{Results}

Specimen source and antibiotic susceptibility profile of MRSA isolates

MRSA isolates obtained in 2016 and 2017 were mostly from skin and soft tissue infection specimens (1983; 41.9\%). This was followed by nasal swabs (1276; 26.9\%), endotracheal specimens $(271 ; 5.7 \%)$, blood $(200 ; 4.2 \%)$, urine (102; $2.1 \%)$, throat $(89 ; 1.8 \%)$ and ear $(64 ; 1.3 \%)$. The clinical sources for 741 (15.6\%) of the isolates were not provided.

The distribution of resistance phenotypes for all MRSA isolates obtained in 2016 and 2017 is shown in Table 1. All isolates were sensitive to vancomycin (MIC: $\leq 2 \mu \mathrm{g} / \mathrm{ml}$ ), teicoplanin (MIC: $\leq 2 \mu \mathrm{g} / \mathrm{ml}$ ) and linezolid. Besides betalactam resistance, most of the MRSA isolates obtained in

Table 1 Distribution of resistance phenotype among MRSA isolates in 2016-2017

\begin{tabular}{|c|c|c|c|c|c|c|c|}
\hline \multirow{2}{*}{$\begin{array}{l}\text { Resistance } \\
\text { phenotype }\end{array}$} & \multicolumn{2}{|c|}{$2016(N=2305)$} & \multicolumn{2}{|c|}{$2017(N=2421)$} & \multicolumn{2}{|c|}{ Total $(N=4726)$} & \multirow[t]{2}{*}{$p$-value } \\
\hline & No. & $\%$ & No. & $\%$ & No. & $\%$ & \\
\hline$P G$ & 2118 & 92 & 2363 & 98 & 4481 & 94.8 & \\
\hline GM & 763 & 33 & 775 & 32 & 1538 & 32.5 & \\
\hline $\mathrm{KM}$ & 974 & 42 & 992 & 41 & 1966 & 41.6 & \\
\hline EM & 912 & 40 & 800 & 33 & 1712 & 36.2 & $\leq 0.05$ \\
\hline$C C(I)$ & 435 & 19 & 366 & 15 & 801 & 16.9 & $\leq 0.05$ \\
\hline $\mathrm{CC}(\mathrm{C})$ & 404 & 18 & 365 & 15 & 769 & 16.2 & $\leq 0.02$ \\
\hline CM & 290 & 13 & 376 & 16 & 666 & 14.1 & $\leq 0.05$ \\
\hline TET & 832 & 36 & 943 & 39 & 1775 & 37.5 & \\
\hline $\mathrm{TP}$ & 861 & 37 & 835 & 35 & 1696 & 35.8 & \\
\hline RF & 12 & 0.5 & 10 & 0.4 & 22 & 0.46 & \\
\hline FA & 1178 & 51 & 1324 & 55 & 2502 & 52.9 & \\
\hline CIP & 854 & 37 & 835 & 35 & 1689 & 35.7 & \\
\hline MUP(L) & 189 & 8 & 221 & 9 & 410 & 8.6 & \\
\hline $\operatorname{MUP}(H)$ & 87 & 3.7 & 59 & 2.4 & 146 & 3.1 & $\leq 0.05$ \\
\hline
\end{tabular}

Abbreviations: $P G$ penicillin G, Gm gentamicin, $K m$ kanamycin, Tet tetracycline, Em erythromycin, $C C$ (I) induced-resistance clindamycin, $C C$ (C) constitutiveresistance clindamycin, $T p$ trimethoprim, $R F$ rifampicin, Fa fusidic acid, CM chloramphenicol, Cip ciprofloxacin, MUP (H) mupirocin high- level resistance, MUP (L) mupirocin low- level resistance 
2016 and 2017 were resistant to fusidic acid (52.9\%). This was followed by resistance to kanamycin (41.6\%), tetracycline (37.5\%), erythromycin (36.2\%), trimethoprim (35.8\%), ciprofloxacin (35.7\%), gentamicin (32.5\%), clindamycin $(16.9 \%)$, and chloramphenicol (14.1\%). Only a small proportion of the isolates expressed high-level resistance (HLR) to mupirocin (3.1\%).

Comparison of the distribution of antibiotic resistance in MRSA isolates obtained between 2016 and 2017 is shown in Table 1. During 2016-2017, there were significant $(p \leq 0.05)$ decrease in the prevalence of resistance to erythromycin, clindamycin and high-level mupirocin resistance, while resistance to chloramphenicol increased significantly (Table 1).

Results of DNA microarray analysis revealed that the high-level mupirocin-resistant isolates were positive for mupA that encodes an alternative isoleucyl-tRNA synthetase (ileS2) which is unaffected by mupirocin. Similarly, resistance to gentamicin, erythromycin and clindamycin, and tetracycline corresponded with the presence of their respective determinants, aacA-aphD, $\operatorname{erm}(A) / \operatorname{erm}(C)$, and $\operatorname{tet}(K) / \operatorname{tet}(M)$. Fusidic acid resistance was mediated by fus $C$ in most of the isolates and by fusB/faR1 in CC80 isolates.

\section{Prevalence of SCCmec types in MRSA isolates in 2016-2017} The dominant SCCmec type among the MRSA isolates obtained in 2016-2017 was SCCmec type IV (47.0\%) (Table 2). This was followed by SCCmec type V (29.8\%), type III (12.1\%) and type VI (9.3\%). SCCmec type II $(0.5 \%)$ and type I $(0.08 \%)$ were detected in small numbers. Thirty-four isolates carried a new combination of $\mathrm{SCC} m e c$ types $(\mathrm{SCC} m e c \mathrm{IV}+\mathrm{V})$.

There were no significant changes in the distribution of SCCmec types I, II, III and V in MRSA isolates between 2016 and 2017 (Table 2). MRSA isolates carrying type VI increased $(p \leq 0.05)$ from $7 \%$ in 2016 to $11.2 \%$ in 2017, while those carrying SCCmec type IV decreased $(p \leq 0.05$ ) from $50 \%$ in 2016 to $44.5 \%$ in 2017 (Table 2).

Table 2 Distribution of SCCmec types among MRSA isolates in 2016-2017

\begin{tabular}{|c|c|c|c|c|c|c|c|}
\hline \multirow{2}{*}{$\begin{array}{l}\mathrm{SCC} \text { ec } \\
\text { types }\end{array}$} & \multicolumn{2}{|l|}{2016} & \multicolumn{2}{|l|}{2017} & \multicolumn{2}{|l|}{ Total } & \multirow[t]{2}{*}{$p$-value } \\
\hline & No. & $\%$ & No. & $\%$ & No. & $\%$ & \\
\hline I & 1 & 0.04 & 3 & 0.1 & 4 & 0.08 & \\
\hline$\|$ & 14 & 0.6 & 10 & 0.4 & 24 & 0.5 & \\
\hline III & 291 & 13 & 282 & 11.7 & 573 & 12.1 & \\
\hline IV & 1148 & 50 & 1077 & 44.5 & 2225 & 47.0 & $\leq 0.05$ \\
\hline V & 701 & 30 & 708 & 29 & 1409 & 29.8 & \\
\hline $\mathrm{Vl}$ & 170 & 7 & 273 & 11.2 & 443 & 9.3 & $\leq 0.05$ \\
\hline$I V+V$ & 12 & 0.5 & 22 & 1 & 34 & 0.7 & \\
\hline ND & - & - & 46 & 2 & 46 & 0.9 & \\
\hline
\end{tabular}

Prevalence of spa types among MRSA isolates in 2016-2017 In total, 382 spa types were identified among the MRSA isolates obtained in 2016-2017. The distribution of the common spa types among the isolates obtained in 2016 and 2017 is shown in Table 3. Spa type t688 (23\%) was the dominant spa type detected in both years. This was followed by t304, t860, t127, t044, t311, t002 and t223 (Table 3). In addition, 354 spa types were detected in less than 10 isolates. Spa types could not be assigned for 118 isolates in both years.

A comparison of the distribution of spa types of MRSA isolates obtained in 2016-2017 presented in Table 3 revealed that the prevalence of spa type t688 increased $(p \leq 0.05)$ from $10.4 \%$ in 2016 to $12.6 \%$ in 2017 , while the proportions of $\mathrm{t} 002$ and 044 were significantly decreased during the 2 years. No significant changes were observed among the other major spa types. Some sporadic spa types were observed in isolates obtained either in 2016 or 2017 as shown in the supplementary Table S1. The association of spa types with specific genotypes is presented in Table S1.

\section{Distribution of MRSA clones in 2016-2017}

The clonal complexes (CCs) of 3004 MRSA isolates obtained in $2016(N=1327)$ and $2017(N=1677)$, selected on the basis of spa types was determined using DNA microarray. The selection included all clinical samples from different hospitals with the same spa type.

Twenty-six clonal complexes (CCs) were obtained in both years. The clonal complexes (CCs) were $\mathrm{CC} 1, \mathrm{CC} 5$, CC6, CC7, CC8, CC9/ST834, CC15, CC22, CC30, CC45, CC49, CC80, CC88, CC96, CC97, CC121, CC152, CC361, CC398, CC509, CC779, CC913, CC1153, CC2198, CC2250/2277 and CC2596. In addition, three sequence types, ST59, ST72 and ST2867 were identified. The distribution of the MRSA clones is shown in supplementary Table (Table S1). The dominant clonal complexes identified in both years were CC5 (833 isolates), CC22 (421 isolates), CC8 (292 isolates), CC1 (248 isolates), CC6 (241 isolates), CC30 (177 isolates), CC80 (177 isolates) and CC97 (171 isolates) (Table S1). The other clonal complexes including CC7, CC9/ST834, CC15, CC45, CC49, CC88, CC96, CC121, CC152, CC361, CC398, CC509, CC779, CC913, CC1153, CC2198, CC2250/2277, CC2596 and the three sequence types ST59, ST72 and ST2867 were less frequently detected among MRSA isolates during 2016 and 2017 (Table S1). The composition of the major clonal complexes is presented below.

\section{Clonal Complex 1 (CC1)}

CC1 consisted of 16 MRSA genotypes. The most common CC1 genotype was CC1-MRSA-V + SCCfus [PVL $\left.{ }^{+}\right]$ (78 isolates) which occurred in 35 isolates in 2016 and 
Table 3 Distribution of spa types among MRSA isolates in 2016-207

\begin{tabular}{|c|c|c|c|c|c|c|c|}
\hline \multirow{2}{*}{$\begin{array}{l}\text { Spa } \\
\text { types }\end{array}$} & \multicolumn{2}{|c|}{2016} & \multicolumn{2}{|c|}{2017} & \multicolumn{2}{|c|}{ Total } & \multirow[t]{2}{*}{$p$-value } \\
\hline & No. & $\%$ & No. & $\%$ & No. & $\%$ & \\
\hline t688 & 240 & 10.4 & 307 & 12.6 & 547 & 23 & $\leq 0.05$ \\
\hline t304 & 211 & 9.1 & 217 & 8.9 & 428 & 18 & \\
\hline t860 & 190 & 8.2 & 204 & 8.4 & 394 & 16.6 & \\
\hline $\mathrm{t} 127$ & 151 & 6.5 & 155 & 6.4 & 306 & 12.9 & \\
\hline t044 & 132 & 5.7 & 98 & 4 & 230 & 9.7 & $\leq 0.05$ \\
\hline t311 & 124 & 5.3 & 119 & 4.9 & 243 & 10.2 & \\
\hline t002 & 103 & 4.4 & 78 & 3.2 & 181 & 7.6 & $\leq 0.05$ \\
\hline t223 & 94 & 4 & 90 & 3.7 & 184 & 7.7 & \\
\hline t267 & 65 & 2.8 & 68 & 2.8 & 133 & 5.6 & \\
\hline t019 & 58 & 2.5 & 58 & 2.3 & 116 & 4.8 & \\
\hline t3841 & 54 & 2.3 & 44 & 1.8 & 98 & 4.1 & \\
\hline t084 & 38 & 1.6 & 55 & 2.2 & 93 & 3.8 & \\
\hline t852 & 35 & 1.5 & 24 & 0.99 & 59 & 2.49 & \\
\hline t945 & 33 & 1.4 & 21 & 0.86 & 54 & 2.26 & \\
\hline $\mathrm{t} 105$ & 27 & 1.17 & 20 & 0.82 & 47 & 1.99 & \\
\hline t032 & 26 & 1.12 & 19 & 0.78 & 45 & 1.9 & \\
\hline t657 & 24 & 1 & 23 & 0.95 & 47 & 1.95 & \\
\hline t359 & 18 & 0.78 & 32 & 1.3 & 50 & 2.08 & \\
\hline t786 & 17 & 0.73 & 8 & 0.33 & 25 & 1.06 & \\
\hline t16187 & 15 & 0.65 & 11 & 0.45 & 26 & 1.1 & \\
\hline t008 & 14 & 0.6 & 21 & 0.86 & 35 & 1.46 & \\
\hline t037 & 14 & 0.6 & 11 & 0.45 & 25 & 1.05 & \\
\hline t018 & 12 & 0.52 & 4 & 0.16 & 16 & 0.68 & \\
\hline t021 & 12 & 0.52 & 14 & 0.57 & 26 & 1.09 & \\
\hline t701 & 12 & 0.52 & 7 & 0.28 & 19 & 0.8 & \\
\hline t11822 & 11 & 0.47 & 5 & 0.2 & 16 & 0.67 & \\
\hline t421 & 11 & 0.47 & 17 & 0.7 & 28 & 1.17 & \\
\hline t315 & 10 & 0.43 & 12 & 0.49 & 22 & 0.92 & \\
\hline t535 & 10 & 0.43 & 11 & 0.45 & 21 & 0.88 & \\
\hline ND & 7 & 0.3 & 111 & 4.5 & 118 & 4.8 & \\
\hline
\end{tabular}

Spa types detected in $<10$ isolates: $\mathrm{t} 024, \mathrm{t} 463, \mathrm{t} 1200, \mathrm{t} 2121, \mathrm{t} 5708, \mathrm{t} 026, \mathrm{t} 7011, \mathrm{t} 10659, \mathrm{t} 13697, \mathrm{t} 17282, \mathrm{t} 985, \mathrm{t} 4407, \mathrm{t} 2849, \mathrm{t} 045, \mathrm{t} 5634, \mathrm{t} 1339, \mathrm{t} 2518, \mathrm{t} 680, \mathrm{t} 068$, $\mathrm{t} 7139, \mathrm{t} 10795, \mathrm{t} 14230, \mathrm{t} 17649, \mathrm{t} 5562, \mathrm{t} 454, \mathrm{t} 310, \mathrm{t} 12219, \mathrm{t} 790, \mathrm{t} 16360, \mathrm{t} 2720, \mathrm{t} 7200, \mathrm{t} 086, \mathrm{t} 729, \mathrm{t} 10888, \mathrm{t} 1427, \mathrm{t} 1816, \mathrm{t} 5608, \mathrm{t} 4557, \mathrm{t} 3175, \mathrm{t} 1247, \mathrm{t} 9228, \mathrm{t} 16861$, $\mathrm{t} 279, \mathrm{t} 7348, \mathrm{t} 088, \mathrm{t} 7342, \mathrm{t} 1120, \mathrm{t} 14392, \mathrm{t} 1830, \mathrm{t} 5673, \mathrm{t} 4565, \mathrm{t} 3379, \mathrm{t} 1309, \mathrm{t} 9867, \mathrm{t} 17330, \mathrm{t} 3107, \mathrm{t} 8731, \mathrm{t} 091, \mathrm{t} 7358, \mathrm{t} 11288, \mathrm{t} 14838, \mathrm{t} 186, \mathrm{t} 570, \mathrm{t} 4867, \mathrm{t} 3562, \mathrm{t} 132$, $\mathrm{t} 012, \mathrm{t} 1752, \mathrm{t} 3235, \mathrm{t} 878, \mathrm{t} 094, \mathrm{t} 7466, \mathrm{t} 114, \mathrm{t} 15181, \mathrm{t} 2164, \mathrm{t} 5704, \mathrm{t} 4892, \mathrm{t} 3782, \mathrm{t} 2526, \mathrm{t} 062, \mathrm{t} 17556, \mathrm{t} 334, \mathrm{t} 902, \mathrm{t} 10028, \mathrm{t} 747, \mathrm{t} 11714, \mathrm{t} 15435, \mathrm{t} 217, \mathrm{t} 578, \mathrm{t} 4955, \mathrm{t} 3825$, $\mathrm{t} 4019, \mathrm{t} 10002, \mathrm{t} 177, \mathrm{t} 345, \mathrm{t} 934, \mathrm{t} 10094, \mathrm{t} 774, \mathrm{t} 118, \mathrm{t} 16302, \mathrm{t} 2177, \mathrm{t} 582, \mathrm{t} 4981, \mathrm{t} 3967, \mathrm{t} 442, \mathrm{t} 10892, \mathrm{t} 189, \mathrm{t} 4018, \mathrm{t} 954, \mathrm{t} 10234, \mathrm{t} 777, \mathrm{t} 11836, \mathrm{t} 16470, \mathrm{t} 2235, \mathrm{t} 605$, $\mathrm{t} 5045, \mathrm{t} 398, \mathrm{t} 4549, \mathrm{t} 975, \mathrm{t} 203, \mathrm{t} 425, \mathrm{t} 9606, \mathrm{t} 10306, \mathrm{t} 8369, \mathrm{t} 121, \mathrm{t} 16606, \mathrm{t} 2413, \mathrm{t} 6071, \mathrm{t} 5146, \mathrm{t} 416, \mathrm{t} 1062, \mathrm{t} 9042, \mathrm{t} 1317, \mathrm{t} 17117, \mathrm{t} 258, \mathrm{t} 1034, \mathrm{t} 853, \mathrm{t} 122, \mathrm{t} 16877, \mathrm{t} 242$, $\mathrm{t} 622, \mathrm{t} 525, \mathrm{t} 422, \mathrm{t} 17281, \mathrm{t} 9207, \mathrm{t} 681, \mathrm{t} 17275, \mathrm{t} 2658, \mathrm{t} 10347, \mathrm{t} 8657, \mathrm{t} 12413, \mathrm{t} 16945, \mathrm{t} 2467, \mathrm{t} 6584, \mathrm{t} 537, \mathrm{t} 4336, \mathrm{t} 2790, \mathrm{t} 9448, \mathrm{t} 6845, \mathrm{t} 17279, \mathrm{t} 2672, \mathrm{t} 10395, \mathrm{t} 8962$, $\mathrm{t} 12743, \mathrm{t} 16946, \mathrm{t} 2529, \mathrm{t} 6675, \mathrm{t} 5414, \mathrm{t} 437, \mathrm{t} 10422, \mathrm{t} 903, \mathrm{t} 13158, \mathrm{t} 17084, \mathrm{t} 2571, \mathrm{t} 6769, \mathrm{t} 547, \mathrm{t} 4403, \mathrm{t} 046, \mathrm{t} 1154, \mathrm{t} 1198, \mathrm{t} 1215, \mathrm{t} 138, \mathrm{t} 16185, \mathrm{t} 1839, \mathrm{t} 2601, \mathrm{t} 3364, \mathrm{t} 362$, $\mathrm{t} 4326$, t8154, t010, t014, t1028, t11863, t1252, t131, t14228, t14700, t1548, t16182, t16186, t16202, t1977, t211, t2393, t3012, t3243, t3387, t355, t3896, t4045, $\mathrm{t} 4724, \mathrm{t} 521, \mathrm{t} 5485, \mathrm{t} 579, \mathrm{t} 639, \mathrm{t} 693, \mathrm{t} 8221, \mathrm{t} 845, \mathrm{t} 8506, \mathrm{t} 9673, \mathrm{t} 004, \mathrm{t} 016, \mathrm{t} 034, \mathrm{t} 050, \mathrm{t} 067, \mathrm{t} 10116, \mathrm{t} 10118, \mathrm{t} 1039, \mathrm{t} 10405, \mathrm{t} 1081, \mathrm{t} 10836, \mathrm{t} 11113, \mathrm{t} 11206, \mathrm{t} 11462$ $\mathrm{t} 1147, \mathrm{t} 1175, \mathrm{t} 11901, \mathrm{t} 12068, \mathrm{t} 12236, \mathrm{t} 12398, \mathrm{t} 12537, \mathrm{t} 13429, \mathrm{t} 13699, \mathrm{t} 1379, \mathrm{t} 14090, \mathrm{t} 144, \mathrm{t} 1476, \mathrm{t} 1504, \mathrm{t} 15069, \mathrm{t} 15224, \mathrm{t} 1556, \mathrm{t} 15778, \mathrm{t} 15801, \mathrm{t} 1588, \mathrm{t} 1593$, $\mathrm{t} 16181, \mathrm{t} 1635, \mathrm{t} 16361, \mathrm{t} 16373, \mathrm{t} 16468, \mathrm{t} 16486, \mathrm{t} 16549, \mathrm{t} 16578, \mathrm{t} 16579, \mathrm{t} 16604, \mathrm{t} 16605, \mathrm{t} 16901, \mathrm{t} 16903, \mathrm{t} 16904, \mathrm{t} 16905, \mathrm{t} 1836, \mathrm{t} 1855, \mathrm{t} 190, \mathrm{t} 1965, \mathrm{t} 1991, \mathrm{t} 214$, $\mathrm{t} 2251$, t228, t253, t2622, t2734, t2770, t2802, t2933, t3010, t3092, t3196, t321, t324, t325, t330, t3494, t3651, t4223, t4224, t4359, t450, t504, t527, t541, t5593, t5772, t586, t591, t5994, t6258, t6670, t6693, t6827, t711, t713, t743, t7604, t7623, t7656, t7685, t779, t8009, t8166, t8168, t8348, t8934, t899, t9231, t9434, t948, t9638

in 43 isolates in 2017. Of the 16 spa types identified among the CC1-MRSA-V + SCCfus $\left[\mathrm{PVL}^{+}\right]$isolates, the t127 was the most common spa type in 2016 and 2017. Spa types $\mathrm{t} 3896, \mathrm{t} 6693, \mathrm{t} 948, \mathrm{t} 1252, \mathrm{t} 693, \mathrm{t} 591$ were only detected in 2016, while t114, t1589, t16861, t177, t2207, t398, t605, t17556, t2658 were only detected in 2017. Other common genotypes of CC1 were CC1-MRSA-V + SCCfus (50 isolates) and CC1-MRSA-IV, WA MRSA-1/57 
(34 isolates). Nineteen CC1-MRSA-V + SCCfus isolates were detected in 2016. This increased to 31 isolates in 2017. They consisted of eight spa types with spa types t1252 detected only in 2016 and t2720, t948, t177, t217, t2720 detected only in 2017 respectively while, spa types t127 and t693 were found in both years. Similarly, strains of CC1-MRSA-IV, WA MRSA-1/57 increased from nine isolates in 2016 to 25 isolates in 2017 and were associated with nine spa types with three spa types t3494, t086 and t688 detected only in 2016 and t1589, t17649, t5388 detected only in 2017. Four novel variants of CC1MRSA were identified. These were CC1-MRSA- $\left[\mathrm{V} / \mathrm{V}_{\mathrm{T}}+\right.$ fus] $\left(\mathrm{PVL}^{+}\right)$, CC1-MRSA-PseudoSCCmec [classB+fus + ccrAB1], CC1-MRSA-[V/V $\mathrm{V}_{\mathrm{T}}+$ fus] and CC1-MRSA-[V/ $\mathrm{V}_{\mathrm{T}}$ + fus + ccrAB1] $\left(\mathrm{PVL}^{+}\right)$. While eight isolates of CC1MRSA-[V/V $\mathrm{V}_{\mathrm{T}}+$ fus] $\left(\mathrm{PVL}^{+}\right)$were detected in 2016, only four of the isolates were detected in 2017. The other genotypes, CC1-MRSA-PseudoSCCmec[classB+fus + ccrAB1], CC1-MRSA-[V/V $\mathrm{V}_{\mathrm{T}}+$ fus], and CC1-MRSA-[V/ $/ \mathrm{V}_{\mathrm{T}}+$ fus + ccrAB1] $\left(\mathrm{PVL}^{+}\right)$were detected only in 2016. The remaining CC1 MRSA strains are presented in Table S1.

A total of 49 isolates of ST772-MRSA-V [PVL ${ }^{+}$, Bengal Bay Clone were identified in 2016 (27 isolates) and 2017 (22 isolates). They consisted of seven spa types. Spa types $\mathrm{t} 10795, \mathrm{t} 345, \mathrm{t} 5414$, t657 were detected in 2016 and 2017 while two spa types, t1839 and t3387 were detected only in 2016 while t17441 was detected only in 2017. Other ST772-MRSA genotypes identified only in 2017 consisted of ST772-MRSA-V, ST772MRSA-V $\left[\mathrm{PVL}^{+}\right]$, Bengal Bay Clone/WA MRSA-60 [ccr mutation/deletion] and ST772-MRSA-[mec $\mathrm{V}+$ fus$]$ $\left(\mathrm{PVL}^{+}\right)$. The ST772-MRSA- [mec V + fus] $\left(\mathrm{PVL}^{+}\right)$strain was identified as a new variant of ST772 in 2017 and belonged to spa type t20638.

\section{Clonal Complex 5 (CC5)}

CC5 consisted of 19 MRSA genotypes with CC5-MRSA$\mathrm{VI}+$ SCCfus (337 isolates) as the dominant genotype. The CC5-MRSA-VI + SCCfus genotype was detected in 87 isolates in 2016 and 250 isolates in 2017 which represented a significant increase. It was associated with 11 spa types with $\mathrm{t} 2235$, t535, t688, t954 found in both years. (Table S1). The other common genotype was CC5-MRSA-V + SCCfus, WA MRSA-14/109 which slightly increased in prevalence from 79 in 2016 to 89 in 2017. CC5-MRSA-IV, $\left[\mathrm{PVL}^{+}\right]$and CC5-MRSA-V $[\mathrm{sed} / \mathrm{j} /$ $\mathrm{r}^{+}$], WA MRSA-11/34/35/90/108 strains increased from 40 and 26 isolates in 2016 to 55 and 42 isolates in 2017 respectively. Four CC5 strains detected only in 2017 were CC5-MRSA-V [PVL ${ }^{+}$, CC5-MRSA-II [ACME ${ }^{+}$, WA MRSA-125 and the new variant strains CC5MRSA-[V/V $\mathrm{V}_{\mathrm{T}}+$ fus] and CC5-MRSA-[II + ccrAB4]. In addition, a new CC5 variant, CC5-MRSA-[V/V $\mathrm{V}_{\mathrm{T}}+$ fus] $\left(\mathrm{PVL}^{+}\right)$was detected in 2016.

\section{Clonal Complex 6 (CC6)}

CC6 consisted of three MRSA genotypes. One strain was identified as MSSA by DNA microarray although phenotypically resistant to cefoxitin which could be due to failure in the hybridization of $m e c A$ gene to the probe. The CC6-MRSA-IV, WA MRSA-51 genotype increased slightly from 100 isolates in 2016 to 136 isolates in 2017. They were associated with 27 spa types detected either in 2016 or 2017 (Table S1). Spa types t10888, t11288, t2849, t304, t701, t6845, t4403, t711, t190 were observed in CC6-MRSA-IV,WA MRSA-51 strains detected both in 2016 and 2017. Two isolates belonging to CC6MRSA-V were detected only in 2017 , while a new variant, CC6-MRSA-[IV + fus + ccrC], was only detected in 2016.

\section{Clonal Complex 8 (CC8)}

Sixteen MRSA genotypes consisting of ST8 $(N=74)$ and ST239 $(N=218)$ were identified as CC8. The distribution of all CC8 strains is presented in Table S1. The most common CC8 genotypes were CC8-MRSA-IV [tst1 ${ }^{+}$] (15 isolates), CC8-MRSA-IV, UK-EMRSA-14/ WA MRSA-5 (13 isolates), and ST8-MRSA-IV [PVL ${ }^{+}$ $\mathrm{ACME}^{+}$], USA300 (11 isolates). The CC8-MRSA-IV $\left[\mathrm{tst}^{+}\right]$genotype was detected in seven isolates in 2016 and in eight isolates in 2017, while CC8-MRSA-IV, UKEMRSA-14/WA MRSA-5 genotype was detected in four isolates in 2016 and nine isolates in 2017. The USA300 genotype was found in two isolates in 2016 and nine isolates in 2017. The CC8 strains found only in 2016 include CC8-MRSA-IV [sea-N315 ${ }^{+}$, CC8-MRSA-IV, $\left[\mathrm{PVL}^{+}, \operatorname{sed} / \mathrm{j} / \mathrm{k} / \mathrm{q} / \mathrm{r}^{+}\right]$, WA MRSA-62 and CC8-MRSA$\left[\mathrm{V} / \mathrm{V}_{\mathrm{T}}+\mathrm{fus}\right]$ (a new variant of $\mathrm{CC} 8$ ), whereas CC8MRSA-VI + SCCfus was identified once in 2017. Other CC8 strains were found in a small number in 2016 and 2017 (Table S1).

A total of 180 isolates were identified as ST239-MRSAIII + SCCmer, Vienna/Hungarian/Brazilian clone. This genotype was found in 101 isolates in 2016 and 79 isolates in 2017. Nine spa types, t1247, t1339, t15224, t6258, t713, t16187, t421, t860, t945 were associated with the ST239MRSA-III + SCCmer, Vienna/Hungarian/Brazilian Clone in 2016, while six spa types, t16187, $\mathrm{t} 421, \mathrm{t} 860, \mathrm{t} 945, \mathrm{t} 037$, t680 were found in 2017. The distribution of the other ST239 strains is shown in Table S1.

\section{Clonal Complex 22 (CC22)}

CC22 consisted of 12 MRSA genotypes with CC22MRSA-IV [tst1 ${ }^{+}$], UK-EMRSA-15/Middle Eastern variant detected in 202 isolates as the most prevalent genotype of CC22. The UK-EMRSA-15/Middle Eastern variant was detected in 89 isolates in 2016 and in 113 isolates in 2017. Another common CC22 genotype was the PVL-positive CC22-MRSA-IV (98 isolates) which was detected in 56 isolates in 2016 and in 42 isolates in 
2017. The CC22-MRSA-V [fusC $\mathrm{C}^{+}$] strain was identified once in 2017. The new variants, CC22-MRSA-IV (tst1/ $\mathrm{PVL}^{+}$) and CC22-MRSA-[VI + fus] detected in 20162017 were found in 25 and four isolates respectively. Another new variant, identified as CC22-MRSA-[IV + fus + ccrAB4], appeared for the first time in 2017.

\section{Clonal Complex 30 (CC30)}

CC30 consisted of seven ST30 and one ST36 MRSA isolates. The most common genotype was the CC30MRSA-IV $\left[\mathrm{PVL}^{+}\right]$, Southwest Pacific Clone (130 isolates) which was detected in 68 isolates in 2016 and in 62 isolates in 2017. The most common spa type identified with this genotype was t019. Three genotypes carrying SCCmecVI with fusC were identified as variants of CC30. Twelve and three isolates were identified as CC30-MRSA-[VI + fus] $\left(\mathrm{PVL}^{+}\right)$in 2016 and 2017 respectively. Four isolates of CC30-MRSA-[VI + fus] $\left(\mathrm{PVL}^{+} /\right.$tst1) were detected only in 2017.

\section{Clonal Complex 80 (CC80)}

PVL-positive and PVL-negative variants of CC80-IVMRSA were identified in 177 isolates in 2016-2017. The CC80-MRSA-IV $\left[\mathrm{PVL}^{+}\right]$, European CA-MRSA Clone (138 isolates) was prevalent among MRSA isolates in 2016 (62 isolates) and 2017 (76 isolates). Spa types t044, t042, t005, t11863, t16186, t3196, t376, t10892, t1200, $\mathrm{t} 15435, \mathrm{t} 416, \mathrm{t} 1247, \mathrm{t} 131, \mathrm{t} 203, \mathrm{t} 639$ were identified in the PVL-positive CC80-MRSA-IV isolates with t044 (95 isolates) as the most common spa type in 2016 and 2017. The PVL-negative CC80-MRSA-IV variant (36 isolates) was found in 13 isolates in 2016 and in 23 isolates in 2017. The CC80-MRSA-(truncated/atypical SCCmec) was identified in two PVL-positive isolates in 2016 and in one PVL-negative isolate in 2017.

\section{Clonal Complex 97(CC97)}

A total of 171 isolates were identified as CC97 with 140 isolates recognized as CC97-MRSA-V [fusC ${ }^{+}$. The other genotypes of CC97, CC97-MRSA-IV, WA MRSA-54/63 and CC97-MRSA-V were found in 11 and 15 isolates respectively in 2016-2017.

\section{Discussion}

This study investigated antibiotic resistance and clonal composition of MRSA isolates obtained from patients in Kuwait public hospitals in 2016-2017. The results revealed some changes in the prevalence of resistance to some antibiotics over the 2 years. Significantly, the prevalence of high-level mupirocin resistance decreased from $3.7 \%$ in 2016 to $2.4 \%$ in 2017 . This is consistent with previous report of low prevalence of high-level mupirocin resistance in Kuwait hospitals in recent years [9]. This is reassuring because it indicates that mupirocin can still be used successfully to control MRSA infections. On the other hand, the prevalence of fusidic acid resistance increased from 51\% in 2016 to $55 \%$ in 2017 which was consistent with previous reports of the high prevalence of fusidic acid resistance in Kuwait hospitals [9]. High prevalence of fusidic acid resistance in MRSA isolated in Kuwait has been suggested to be due to several factors including the emergence or importation of many MRSA genotypes that are resistant to fusidic acid in Kuwait hospitals [10], and the extensive use of topical fusidic acid creams that are readily available over the counter without prescription in Kuwait.

Most of the MRSA isolates in this study carried SCCmec IV, V and VI indicating that the majority of the isolates belonged to the community-associated MRSA genotypes. The significant increase in the proportion of isolates carrying SCCmec VI from 2016 to 2017 could be explained by the increase in the number of CC5 isolates with SCCmec VI.

The majority of the isolates obtained in the 2 years belonged to spa types t688, t304, t860, t127, t044, t311, t223 and t002 that were also dominant previously in Kuwait hospitals [5]. Most of the CC5 isolates detected in this study were of spa type t688. In contrast, t002 was the dominant spa type of CC5-MRSA obtained in New Zealand [11], Switzerland [12] and Canada [13]. However, similar to the findings of this study, t688 is also a common spa type among MRSA isolates reported in Egypt [14], a country with a large population of expatriates in Kuwait.

The established eight dominant MRSA clones consisting of CC1, CC5, CC6, CC8/ST239, CC22, CC30, CC80 and CC97 [15-19] were also the dominant clones in Kuwait hospitals in 2016 and 2017 and have been present in Kuwait since the early 2000's [5] indicating that these clones are now well established in Kuwait hospitals.

CC5 is one of the dominant and widely spread MRSA clones reported worldwide [15-19]. In this study, the CC5-MRSA isolates significantly increased $(p \leq 0.05)$ from 294 isolates in 2016 to 539 isolates in 2017 which could be due to the introduction of new CC5 strains in 2017.

We detected CC5-MRSA-II $\left[\mathrm{ACME}^{+}\right]$genotype for the first time in Kuwait in this study. The strain is similar to the pandemic ST5-MRSA-II clone that was reported previously in China and USA [19]. In addition, other CC5 genotypes, including CC5-MRSA-IV + SCCfus, Maltese Clone, CC5-MRSA-IV, $\left[\mathrm{PVL}^{+} / \mathrm{edinA}^{+}\right]$, WA MRSA-121, and CC5-MRSA-V + SCCfus, WA MRSA$14 / 109$, reported in this study were also reported in Saudi Arabia [20-22] suggesting that these clones maybe common in the Arabian Peninsula. 
The study revealed a significant reduction in the proportion of CC8 and CC30 isolates in Kuwait hospitals during the study period. CC8 (ST239-MRSA-III) was the predominant clone among MRSA isolates obtained in Kuwait hospitals in the 90's but its prevalence has since reduced [5]. The low prevalence of ST239-MRSA-III isolates observed in both 2016 and 2017 confirms its decline as a major contributor to MRSA infections in Kuwait hospitals although it is still a major cause of health-associated infections elsewhere [23].

The USA300 (ST8-MRSA-IV $\left[\mathrm{PVL}^{+} / \mathrm{ACME}^{+}\right]$) clone, the dominant CA-MRSA clone in North America [24] was detected for the first time in Kuwait in 2010 [5]. Although the number of USA300 isolates detected in 2017 $(N=9)$ remained remarkably low, it represents a significant increase on the single isolate obtained in 2010. As the USA300 is an important cause of infections, it is important to monitor its prevalence among patients in Kuwait hospitals.

The CC22-MRSA-IV is a well-known epidemic MRSA clone that emerged in the United Kingdom in the early 1990s [25] and soon became prevalent in other European countries [26-28]. Although CC22-MRSA was the second most common clonal complex in this study (421 isolates) similar to results of a previous study in Kuwait [5], their genotypes have increased from three genotypes identified in 2005 and 2010 [29] to 11 different genotypes in 2016 and 2017 with the CC22-MRSA-IV [tst1 ${ }^{+}$], UK-EMRSA-15/Middle Eastern variant still the most common genotype. The tst-positive ST22-MRSA-IV, Middle Eastern variant is also common in Saudi Arabia [21], Gaza strip [30] and Jordan [31]. In contrast, there were no remarkable changes in the distribution of the other CC22 MRSA variants, CC22-MRSA-IV (tst1/ $\mathrm{PVL}^{+}$), CC22-MRSA-[VI + fus], CC22-MRSA-[IV + fus + ccrAB4] in 2016-2017.

The proportion of isolates belonging to CC80-MRSAIV and CC97-MRSA-V remained stable in 2016 and 2017. However, new spa types were seen for the first time in 2017 associated with these strains suggesting changes in their genetic composition. Furthermore, 45 isolates belonging to $\mathrm{CC} 1, \mathrm{CC} 5, \mathrm{CC} 8, \mathrm{CC} 22, \mathrm{CC} 45$, CC88, CC9/ST834 and ST72 carried spa types in 2016 that were different from those obtained in 2017 (Table $\mathrm{S} 1)$. For example, the three isolates belonging to CC1MRSA-V $\left[\mathrm{PVL}^{+}\right]$obtained in 2016 were associated with t127, t321, t386 while one isolate obtained in 2017 was associated with t2720. The CC9/ST834-MRSA-IV, WA MRSA-13 isolate obtained in 2016 was associated with t1379, while in 2017 it was associated with t1830. CC88MRSA-V isolate obtained in 2016 was associated with t3153, while in 2017 it was associated with t6769. Also, ST72-MRSA-V, WA MRSA-91 was associated with t3092 in 2016 but with t537 in 2017. These observations suggest that the isolates obtained in both years were different although they belonged to the same clonal complex. This may impact proper management of infection caused by these isolates. Similar observation was seen in isolates belonging to CC5-MRSA-IV, Pediatric clone, CC8-MRSA-IV [sea ${ }^{+}$, Lyon Clone/UK-EMRSA-2, CC8MRSA-V, WA MRSA-115/-132, ST8-MRSA-IV [PVL+/ ACME-], CC22-MRSA-[VI + fus], CC22-MRSA-IV + V $\left[\mathrm{PVL}^{+}\right]$, CC45/agrIV-MRSA-IV, WA MRSA-23, and CC88-MRSA-[IV + fus] (Table S1).

\section{Conclusion}

The study revealed the diversity in the genetic backgrounds of MRSA isolates and the stable maintenance of the dominant MRSA clones in Kuwait hospitals in 2016-2017 suggesting an on-going transmission of these clones. It also demonstrated the emergence of new variants of known genotypes in Kuwait hospitals in 2016 and 2017. Novel and creative infection prevention and control measures are required to curtail further transmission. It is still not clear why some MRSA clones are able to persist while others fail to survive in the healthcare environment. This warrants further investigations to identify the factors that contribute to the spread and maintenance of the successful MRSA clones.

\section{Methods}

\section{Sample collection}

In total, 4726 single patients, MRSA isolates were obtained from different clinical samples submitted to the clinical Microbiology diagnostic laboratory in 11 Public hospitals in Kuwait in $2016(N=2305)$ and $2017(N=$ 2421). The isolates were identified using biochemical tests and tube coagulase at the diagnostic microbiology laboratory. Once it was identified as MRSA in the diagnostic laboratories, the isolates were sent to the MRSA Reference Laboratory located in the Department of Microbiology, Faculty of Medicine, Kuwait University for molecular typing where they were retested and confirmed as MRSA. The isolates were sub-cultured twice on brain-heart infusion agar (BHIA) plates to obtain pure colonies and incubated at $35^{\circ} \mathrm{C}$ for $18 \mathrm{~h}$. Pure cultures were preserved in beads and stored at $-20^{\circ} \mathrm{C}$ and $-80^{\circ} \mathrm{C}$. They were recovered on brain-heart infusion agar (BHIA) and incubated at $35^{\circ} \mathrm{C}$ prior to further testing.

\section{Antibiotic susceptibility testing}

Susceptibility to penicillin G, gentamicin, kanamycin, erythromycin, clindamycin, tetracycline, fusidic acid, trimethoprim, mupirocin, ciprofloxacin, chloramphenicol, rifampicin, cefoxitin, linezolid, vancomycin and teicoplanin were tested using the disc diffusion method according to the Clinical Laboratory Standards Institute 
(CLSI) [32]. Susceptibility to cefoxitin, vancomycin, teicoplanin, and mupirocin were confirmed by minimum inhibitory concentration (MIC) determination with Etest strips (BioMerieux, Marcy l'Etoile, France) according to the manufacturer's instructions. S. aureus strain ATCC25923 and ATCC29213 were used as quality control strains for the disc diffusion and MIC determination, respectively. Susceptibility to fusidic acid was interpreted according to the British Society to Antimicrobial Chemotherapy (BSAC) [33].

\section{Staphylococcal cassette chromosome mec (SCCmec) typing}

SCCmec typing was performed using PCR for all MRSA isolates. Six types of SCCmec was determined by multiplex PCR using primers and protocols published previously [34]. Five $\mu \mathrm{l}$ of the PCR product was analyzed by $1.5 \%$ agarose gel electrophoresis to confirm amplification. Five $S$. aureus strains represented by COL (SCCmec I), XU642 (SCCmec II), WBG 525 (SCCmec III), WBG 9465 (SCCmec IV), WBG 8318 (SCCmec V) were used as quality control for each SCCmec type. The SCCmec types of the isolates were also derived from DNA microarray analysis.

\section{Staphylococcal protein a (spa) typing}

All MRSA isolates were investigated by spa typing. Amplification of spa gene was performed using synthetic primers previously published [35]. The PCR protocol consisted of an initial denaturation at $94{ }^{\circ} \mathrm{C}$ for $4 \mathrm{~min}$, followed by 25 cycles of denaturation at $94{ }^{\circ} \mathrm{C}$ for $1 \mathrm{~min}$, annealing at $56^{\circ} \mathrm{C}$ for $1 \mathrm{~min}$, and extension for $3 \mathrm{~min}$ at $72{ }^{\circ} \mathrm{C}$, and a final cycle with a single extension for $5 \mathrm{~min}$ at $72{ }^{\circ} \mathrm{C}$. Five $\mu \mathrm{l}$ of the PCR product was analyzed by $1.5 \%$ agarose gel electrophoresis to confirm amplification. The amplified PCR product was purified using MicroElute Cycle-Pure Spin kit (Omega Bio-tek, Inc. USA) and the purified DNA was then used for sequencing PCR. The sequencing PCR product was then purified using Ultra-Sep Dye Terminator Removal kit (Omega Bio-tek, Inc. USA). The Purified DNA was sequenced in an automated $3130 \times 1$ genetic analyzer (Applied Biosystem, USA). The sequence of spa gene was analyzed using the Ridom Staph Type software (Ridom GmbH, Wurzburg, Germany). The software detected the spa repeat and assigned each isolate with spa type.

\section{DNA microarray}

Based on spa typing, representative MRSA isolates obtained in 2016 and 2017 were subjected to DNA microarray to determine their clonal complex (CC) using the S. aureus Genotyping kit 2.0 (Alere, GmbH, Germany) with a protocol provided by the manufacturer [36].

\section{Statistical analysis}

To determine if the difference in the distribution of the isolates obtained in 2016 and 2017 is statistically significant, 2-tailed Chi square and Fisher exact was performed using Graphpad (https://www.graphpad.com/quickcalcs/ catMenu/). Also, the significance was calculated by comparing the proportions between two sample sizes using Epicalc 2000 Version 1.02 (J \& Myatt M, Brixton Books, Brixton, UK). $P \leq 0.05$ was considered to be statistically significant.

\section{Supplementary information}

Supplementary information accompanies this paper at https://doi.org/10. 1186/s12866-020-02009-w.

Additional file 1: Table S1. Distribution oc clonal complexes (CCS) among MRSA isolates 2016-2017.

\section{Abbreviations}

MRSA: Methicillin-resistant Staphylococcus aureus; HA-MRSA: Healthcareassociated or healthcare-acquired MRSA; CA-MRSA: Community-associated or community-acquired MRSA; spa: Staphylococcal protein A; MLST: Multilocus sequence typing; PFGE: Pulsed-filed gel electrophoresis; CC: Clonal Complex; MIC: Minimum inhibitory concentration

\section{Acknowledgments}

The authors are grateful to the technical staff in the MRSA Reference Laboratory located in Microbiology department located in Faculty of Medicine for their technical assistance.

Authors' contributions

Laboratory work: SB, Data analysis: SB, Experimental design: EU, Manuscript writing and editing: SB, WA, EU. All authors read and approved the final manuscript.

\section{Funding}

This study was not funded by any external organization or institution.

Availability of data and materials

All relevant data are available in the manuscript and supplementary file.

Ethics approval and consent to participate

This study did not involve human participants, human data or human tissue; thus ethical approval was not required. All the MRSA isolates were obtained as part of routine diagnostic microbiology investigations.

Consent for publication

Not Applicable.

\section{Competing interests}

The authors declare that they have no competing interests.

Received: 19 February 2020 Accepted: 12 October 2020

Published online: 16 October 2020

References

1. Jevons MP. Celbenin-resistant staphylococci. Br Med J. 1961;1:124-5

2. Lakhundi S, Zhang K. Methicillin-resistant Staphylococcus aureus: molecular characterization, evolution, and epidemiology. Clin Microbiol Rev. 2018; 31(4):e00020-18.

3. Gordon RJ, Lowy FD. Pathogenesis of methicillin-resistant Staphylococcus aureus infection. Clin Infect Dis. 2008;46(Suppl 5):S350-9.

4. Udo EE, Pearman JW, Grubb WB. Genetic analysis of community isolates of methicillin-resistant Staphylococcus aureus in Western Australia. J Hosp Infect. 1993;25:97-108 
5. Boswihi SS, Udo EE, Al-Sweih N. Shifts in the clonal distribution of methicillin-resistant Staphylococcus aureus in Kuwait hospitals: 1992-2010. PLoS One. 2016;11(9):e0162744.

6. Hsu LY, Koh TH, Kurup A, Low J, Chlebicki MP, Tan BH. High incidence of Panton-valentine leukocidin-producing Staphylococcus aureus in a tertiary care public hospital in Singapore. Clin Infect Dis. 2005:40(3):486-9.

7. Sonnevend A, Blair I, Alkaabi M, Jumaa P, Al Haj M, Ghazawi A, et al. Change in meticillin-resistant Staphylococcus aureus clones at a tertiary care hospital in the United Arab Emirates over a 5-year period. J Clin Pathol. 2012;65(2): $178-82$.

8. Aires de Sousa M, Correia B, de Lencastre $H$. Changing patterns in frequency of recovery of five methicillin-resistant Staphylococcus aureus clones in Portuguese hospitals: surveillance over a 16-year period. J Clin Microbiol. 2008;46(9):2912-7.

9. Udo EE, Boswihi SS. Antibiotic resistance trends in methicillin-resistant Staphylococcus aureus isolated in Kuwait hospitals: 2011-2015. Med Princ Pract. 2017;26(5):485-90.

10. Boswihi SS, Udo EE, Monecke S, Mathew B, Noronha B, Verghese T, Tappa SB. Emerging variants of methicillin-resistant Staphylococcus aureus genotypes in Kuwait hospitals. PLoS One. 2018;13(4):e0195933.

11. Heffernan H, Bakker S, Dyet K, Williamson D. Annual survey of methicillinresistant Staphylococcus aureus (MRSA), 2015. Porirua: Nosocomial Infections Laboratory, Institute of Environmental Science and Research Ltd.; 2016.

12. Seidl K, Leimer N, Palheiros Marques M, Furrer A, Holzmann-Burgel A, Senn $\mathrm{G}$, et al. Clonality and antimicrobial susceptibility of methicillin-resistant Staphylococcus aureus at the University Hospital Zurich, Switzerland between 2012 and 2014. Ann Clin Microbiol Antimicrob. 2015;14:14

13. Asadollahi P, Farahani NN, Mirzaii M, Khoramrooz SS, van Belkum A, Asadollahi K, Dadashi M, Darban-Sarokhalil D. Distribution of the Most Prevalent Spa Types among Clinical Isolates of Methicillin-Resistant and -Susceptible Staphylococcus aureus around the World: A Review. Front Microbiol. 2018;12(9):163.

14. Abou Shady HM, Bakr AE, Hashad ME, Alzohairy MA. Staphylococcus aureus nasal carriage among outpatients attending primary health care centers: a comparative study of two cities in Saudi Arabia and Egypt. Braz J Infect Dis. 2015:19:68-76.

15. Arias CA, Reyes J, Carvajal LP, Rincon S, Diaz L, Panesso D, et al. A prospective cohort multicenter study of molecular epidemiology and Phylogenomics of Staphylococcus aureus bacteremia in nine Latin American countries. Antimicrob Agents Chemother. 2017;61(10):e00816-7.

16. Chambers HF, Deleo FR. Waves of resistance: Staphylococcus aureus in the antibiotic era. Nat Rev Microbiol. 2009;7(9):629-41.

17. Ko KS, Lee JY, Suh JY, Oh WS, Peck KR, Lee NY, et al. Distribution of major genotypes among methicillin-resistant Staphylococcus aureus clones in Asian countries. J Clin Microbiol. 2005:43(1):421-6.

18. Dai Y, Liu J, Guo W, Meng H, Huang Q, He L, et al. Decreasing methicillinresistant Staphylococcus aureus (MRSA) infections is attributable to the disappearance of predominant MRSA ST239 clones, Shanghai, 2008-2017. Emerg Microbes Infect. 2019;8(1):471-8.

19. Monecke S, Coombs G, Shore AC, Coleman DC, Akpaka P, Borg M, et al. A field guide to pandemic, epidemic and sporadic clones of methicillinresistant Staphylococcus aureus. PLoS One. 2011;6(4):e17936.

20. Monecke S, Skakni L, Hasan R, Ruppelt A, Ghazal SS, Hakawi A, et al. Characterisation of MRSA strains isolated from patients in a hospital in Riyadh, Kingdom of Saudi Arabia. BMC Microbiol. 2012;12:146.

21. Senok A, Ehricht R, Monecke S, Al-Saedan R, Somily A. Molecular characterization of methicillin-resistant Staphylococcus aureus in nosocomial infections in a tertiary-care facility: emergence of new clonal complexes in Saudi Arabia. New Microbes New Infect. 2016:14:13-8.

22. Senok A, Somily AM, Nassar R, Garaween G, Kim Sing G, Muller E, et al. Emergence of novel methicillin-resistant Staphylococcus aureus strains in a tertiary care facility in Riyadh, Saudi Arabia. Infect Drug Resist. 2019; 12:2739-46

23. Khokhlova OE, Hung WC, Wan TW, Iwao Y, Takano T, Higuchi W, et al. Healthcare- and community-associated methicillin-resistant Staphylococcus aureus (MRSA) and fatal pneumonia with pediatric deaths in Krasnoyarsk, Siberian Russia: unique MRSA's multiple virulence factors, genome, and stepwise evolution. PLoS One. 2015;10(6):e0128017.

24. Carrel M, Perencevich EN, David MZ. USA300 methicillin-resistant Staphylococcus aureus, United States, 2000-2013. Emerg Infect Dis. 2015. 21(11):1973-80.
25. Richardson JF, Reith S. Characterization of a strain of methicillin-resistant Staphylococcus aureus (EMRSA-15) by conventional and molecular methods. J Hosp Infect. 1993;25:45-52.

26. Campanile F, Bongiorno D, Borbone S, Stefani S. Hospital-associated methicillin-resistant Staphylococcus aureus (HA-MRSA) in Italy. Ann Clin Microbiol Antimicrob. 2009;8:22.

27. Johnson AP, Aucken HM, Cavendish S, Ganner M, Wale MC, Warner M, et al. Dominance of EMRSA-15 and -16 among MRSA causing nosocomial bacteraemia in the UK: analysis of isolates from the European antimicrobial resistance surveillance system (EARSS). J Antimicrob Chemother. 2001;48:143-4.

28. Melter O, Urbaskova P, Jakubu V, Mackova B, Zemlickova H. Emergence of EMRSA-15 clone in hospitals throughout the Czech Republic. Euro Surveill. 2006;11(8):E060803.6

29. Udo EE, Boswihi SS, Al-Sweih N. High prevalence of toxic shock syndrome toxin-producing epidemic methicillin-resistant Staphylococcus aureus 15 (EMRSA-15) strains in Kuwait hospitals. New Microbes New Infect. 2016;12: 24-30.

30. Biber A, Abuelaish I, Rahav G, Raz M, Cohen L, Valinsky L, et al. A typical hospital-acquired methicillin-resistant Staphylococcus aureus clone is widespread in the community in the Gaza strip. PLoS One. 2012;7(8):e42864

31. Aqel AA, Alzoubi HM, Vickers A, Pichon B, Kearns AM. Molecular epidemiology of nasal isolates of methicillin-resistant Staphylococcus aureus from Jordan. J Infect Public Health. 2015;8(1):90-7.

32. Clinical and Laboratory Standard Institute. Performance standards for antimicrobial susceptibility testing: twenty-second informational supplement M100-S25. Wayne: CLSI; 2015.

33. British Society to Antimicrobial Chemotherapy (BSAC) (BSAC, 2013). http:// bsac.org.uk/susceptibility. Accessed 30 Jan 2020.

34. Zhang K, McClure JA, Elsayed S, Louie T, Conly JM. Novel multiplex PCR assay for characterization and concomitant subtyping of staphylococcal cassette chromosome mec types I to $\mathrm{V}$ in methicillin-resistant Staphylococcus aureus. J Clin Microbiol. 2005;43(10):5026-33.

35. Harmsen D, Claus H, Witte W, Rothganger J, Claus H, Turnwald D, et al. Typing of methicillin-resistant Staphylococcus aureus in a university hospital setting by using novel software for spa repeat determination and database management. J Clin Microbiol. 2003:41(12):5442-8.

36. Monecke S, Jatzwauk L, Weber S, Slickers P, Ehricht R. DNA microarray-based genotyping of methicillin-resistant Staphylococcus aureus strains from eastern Saxony. Clin Microbiol Infect. 2008;14:534-45.

\section{Publisher's Note}

Springer Nature remains neutral with regard to jurisdictional claims in published maps and institutional affiliations.

Ready to submit your research? Choose BMC and benefit from

- fast, convenient online submission

- thorough peer review by experienced researchers in your field

- rapid publication on acceptance

- support for research data, including large and complex data types

- gold Open Access which fosters wider collaboration and increased citations

- maximum visibility for your research: over $100 \mathrm{M}$ website views per year

At $\mathrm{BMC}$, research is always in progress.

Learn more biomedcentral.com/submissions 